\title{
Automated Animal Control: Can Discontinuous Monitoring and Aversive Stimulation Modify Cattle Grazing Behavior?
}

\author{
Jabier Ruiz-Mirazo, ${ }^{1}$ Greg J. Bishop-Hurley, ${ }^{2}$ and Dave L. Swain ${ }^{3}$
}

Authors are ${ }^{1}$ Researcher, CSIC-Estación Experimental del Zaidin, C/Profesor Albareda 1, E-18008 Granada, Spain; ${ }^{2}$ Research Scientist, CSIRO Livestock Industries, QCAT, PO Box 883, Kenmore, QLD 4069, Australia; and ${ }^{3}$ Senior Research Fellow, Centre for Environmental Management, CQ University, Rockhampton, QLD 4701, Australia.

\begin{abstract}
Grazing livestock freely select landscape resources, unless they are herded or constrained by fences. Automated animal control (AAC) systems offer an alternative to physical fences by using animal-positioning technology and aversive stimuli to deter animals from staying in sensitive environments and so limit their impact. This paper reports on a replicated field experiment completed to test whether occasional stimuli (audio cue followed by a mild electric stimulus), delivered by discontinuously activated AAC collars, could suffice to modify the grazing behavior of groups of cattle. Four groups of eight steers were confined in 8-ha rectangular paddocks that had an ad libitum supplement feeder located in one end to attract cattle. The steers' positional information was recorded continuously for $3 \mathrm{~d}$ using a GPS receiver encased in a collar fitted around their neck. These data were used to characterize their use of the paddocks without intervention. Subsequently a restriction zone was activated on the collars. This zone contained the supplement feeders and represented approximately $10 \%$ of the paddock area. Cattle movement was again monitored during a second $3-\mathrm{d}$ period, in which the steers were subjected to discontinuous aversive stimuli $(5 \mathrm{~min}$ of stimulation followed by a random 0-30 min interval without stimulation) if they were located inside or moved into the restriction zone. Cattle visits to the restriction zone were shorter and the return interval longer when steers were subjected to discontinuous stimulation. Overall, there was a $97 \%$ reduction in the use of the restriction zone between the first and second deployments. These results suggest that grazing impact can be drastically reduced by making a zone less desirable through discontinuous aversive stimulation. Such a discontinuous ( $25 \%$ of the time on) AAC system can reduce power consumption in collars and so help overcome energy supply limitations that hinder commercial AAC applications.
\end{abstract}

\section{Resumen}

El ganado en pastoreo selecciona libremente los recursos disponibles, salvo que sea pastoreado o se mantenga en potreros. Los sistemas de Control Animal Automatizado (CAA) ofrecen una alternativa a los cercados físicos mediante el empleo de tecnología de posicionamiento animal y estímulo desagradable para evitar que los animales permanezcan en entornos sensibles, limitando así su impacto. Este trabajo reporta un experimento de campo replicado en el que se comprobó si estímulos ocasionales (un indicador auditivo seguido de una suave descarga eléctrica), generados por collares CAA activados de forma discontinua, bastaban para modificar el comportamiento en pastoreo de grupos de ganado. Se introdujeron cuatro grupos de ocho novillos en potreros de 8 ha de superficie cercados rectangularmente y que contenían en un extremo un comedero que ofrecía suplemento ad libitum para atraer a los animales. La información posicional de los animales se registró durante tres días mediante un receptor GPS colocado en un collar alrededor de su cuello. Estos datos se utilizaron para caracterizar la utilización de los pastizales sin intervención. Posteriormente, se activó en los collares una zona de restricción. Esta zona contenía los comederos y representaba aproximadamente un $10 \%$ de la superficie del pastizal. El movimiento del ganado volvió a monitorizarse durante un segundo período de tres días, en el cual se aplicó a los animales estímulos desagradables de forma discontinua ( 5 minutos de estimulación seguidos de un intervalo de 0-30 minutos sin estimulación) si se encontraban en el interior de la zona de restricción o entraban en ella. Las visitas del ganado a la zona de restricción fueron más breves y el intervalo de retorno más largo cuando se les aplicó la estimulación discontinua. En general, se produjo una reducción del $97 \%$ en el uso de la zona entre el primer y segundo períodos experimentales. Estos resultados sugieren que el impacto de pastoreo puede reducirse de manera drástica si se disminuye el atractivo de una zona mediante una estimulación discontinua desagradable. Un sistema de CAA discontinuo como el que se llevo a cabo ( $25 \%$ del tiempo en funcionamiento) puede reducir el consumo de energía y ayudar así a superar las limitaciones de suministro energético que dificultan que el CAA sea aplicado comercialmente.

Key Words: animal distribution, avoidance behavior, electronic collars, grazing impact, landscape preference index, virtual fencing

J.R.-M. was sponsored by a European Social Fund cofunded postgraduate I3P grant from the Consejo Superior de Investigaciones Científicas (CSIC).

At the time of this research, G.J.B-H. and D.L.S. were Research Scientists and J.R-M. was Visiting Researcher, CSIRO Livestock Industries, JM Rendel Laboratory, Ibis Avenue, North Rockhampton, QLD 4701, Australia.

Correspondence: Greg Bishop-Hurley, CSIRO Livestock Industries, QCAT, PO Box 883, Kenmore, QLD 4069, Australia. Email: Greg.Bishop-Hurley@csiro.au

Manuscript received 24 May 2010; manuscript accepted 25 January 2011.

\section{INTRODUCTION}

The natural distribution of foraging animals across a landscape develops from choices animals make after evaluating tradeoffs between the different resources available. These choices are based on the interaction of biotic factors such as forage biomass or nutritive quality and abiotic factors such as topography, water availability, or microclimate (Senft et al. 
1987). Comparing the time animals spend in a particular zone with its relative surface area in the landscape is a frequent approach to assessing animal preference for particular resources (Pienaar et al. 1992; Handcock et al. 2009). For wildlife, the highest density of a species often suggests optimal habitat. However, sustainable management of grazing livestock requires a managed distribution of animals across the landscape to avoid overgrazing certain areas and to make the best use of the pastoral resources available (Bailey 2005).

Therefore, modifying natural grazing distribution is frequently regarded as necessary for several management objectives, such as protecting areas sensitive to grazing, matching stocking rate with carrying capacity across a property, or scheduling targeted grazing to reduce fuel loads and the risk of wildfire (Ruiz-Mirazo et al. 2009). Traditionally, herding and fencing have been successfully used to manage livestock movements. However, other techniques such as placing supplements or drinking water in key locations, or improving pasture quality in some areas, can also modify livestock distribution (DelCurto et al. 1999; Ganskopp 2001; Bailey 2005). The development of technology may offer further costefficient alternatives for extensive livestock farming systems. For example, sensor networks and other information communication technologies have been proposed for low-labor livestock systems, so as to improve their productivity by increasing the awareness on the state of both pastures and animals (Wark et al. 2007; Handcock et al. 2009).

Automated animal control (AAC), a wider term for virtual fencing, is a relatively recent technological development (Butler et al. 2006) designed to provide an alternative to conventional fencing. In AAC systems, a virtual boundary is usually defined by geographic coordinates, the location of an animal is monitored via a satellite global positioning system (GPS), and a sensory stimulus is applied using electronics housed in a device worn by the animal (frequently a collar) when an animal enters a restriction zone. Location data can be obtained at an ever decreasing cost through GPS technology, while different combinations of sensory stimuli (e.g., audio, electric, vibration, or light followed by an electric stimulus) have been found to be successful at eliciting a flight response in cattle (Butler et al. 2006; Bishop-Hurley et al. 2007; Lee et al. 2007). Even though AAC is not yet commercially available, it could become a practical alternative to physical fences in the future, particularly where fence installation and maintenance is expensive, more customizable animal control is needed, or fences are an issue for wildlife or recreation. Research into AAC is still needed to optimize the animal-borne equipment, develop an optimal suite of sensory cues to elicit a consistent behavioral response, and improve power sources and efficiency (Anderson 2007).

To date, most AAC experiments have been conducted on relatively small numbers of animals and for relatively short periods of time. Very precise data have been obtained from AAC devices, but at a very high battery power cost (Swain et al. 2008b). To prevent animals crossing a virtual fence, detailed continuous behavioral control algorithms have been mostly researched (Butler et al. 2006; Anderson 2007; Bishop-Hurley et al. 2007). Deriving AAC applications that can work at larger spatial and temporal scales, however, requires a more pragmatic approach to animal control.
Discontinuous AAC operation (i.e., an AAC system where the devices remain in stand-by during part of the deployment time) may provide a useful approach to address power efficiency, a practical constraint that is limiting more widespread use of AAC. Rather than maintaining the virtual fence activated continuously and, thus, stimulating animals as soon as they attempt to enter a restriction zone, discontinuous AAC would involve allowing animals to enter the zone occasionally. This approach moves away from previous research that aimed to obtain complete control of livestock along a virtual fence line. The focus is set on reducing grazing impact on a zone delimited by a permeable virtual boundary, with the use of discontinuous AAC. The smaller the proportion of time AAC devices remained activated $(1 / 2,1 / 4,1 / 10)$, the longer the deployment time would be extended $(\times 2, \times 4, \times 10)$ based on the energy saved.

Nevertheless, the effectiveness of discontinuous AAC in reducing animal use of a restriction zone remains unknown. The mechanisms that initiate and determine the degree of avoidance are still not well understood (Swain et al. 2008a), but animals could be expected to progressively learn, through negative reinforcement, to avoid an area where an aversive stimulus is occasionally delivered (Launchbaugh and Howery 2005; Broom and Fraser 2007). The main objective of this paper is to use a replicated experimental design to determine the effectiveness of discontinuous AAC. Our hypothesis was that occasional cue (stimulus) and control (aversive stimulus) packages, delivered by discontinuously activated AAC devices, could suffice to significantly modify the grazing behavior of groups of cattle and reduce their preference for a restriction zone.

Automated animal control collars were deployed on four groups of cattle, which were under very similar experimental conditions (paddock size and configuration, handling procedures, etc.). Access to an area in the paddocks containing an attractive supplement was first unlimited and later restricted using the discontinuous stimuli provided by AAC collars. If cattle responded consistently and their use of the restriction zone was effectively reduced, the discontinuous AAC operation would be scientifically supported. This would validate this approach to improve power efficiency in AAC systems and open the way for further research that could make this novel technology commercially applicable in the future.

\section{METHODS}

\section{Experimental Site}

The experiment was conducted at the Belmont Research Station (lat $23^{\circ} 13^{\prime} \mathrm{S}$, long $150^{\circ} 23^{\prime} \mathrm{E}, 15 \mathrm{~m}$ a.s.l.), located $20 \mathrm{~km}$ NW of Rockhampton in Queensland, Australia. Four adjacent rectangular paddocks $(645 \mathrm{~m} \mathrm{E}-\mathrm{W} \times 120 \mathrm{~m} \mathrm{~N}-\mathrm{S})$ of $7.6 \mathrm{ha} \pm 0.3 \mathrm{SD}$ and flat relief were used for the experiment. Larger paddocks available at the Research Station were inadequate for a replicated experiment due to their dissimilar sizes and configuration. The experiment was conducted between 18 and 28 November 2008, a period with $98 \mathrm{~mm}$ of rainfall and ambient air temperatures ranging from $13.5^{\circ} \mathrm{C}$ to $36.2^{\circ} \mathrm{C}$ (mean $26.0^{\circ} \mathrm{C}$ ).

Throughout the experiment, cattle grazed on Rhodes grass (Chloris gayana Kunth) pastures with uniform and abundant 


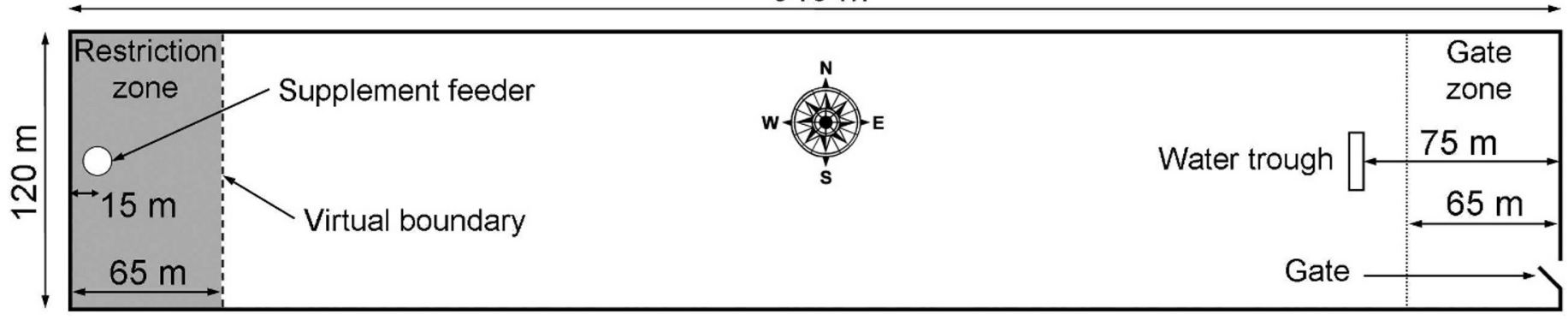

Figure 1. Configuration of the experimental paddocks.

standing crop. An intake-restricted liquid molasses supplement, designed to provide cattle with supplementary protein, essential trace minerals, and vitamins $(40 \%$ sour [cow/calf] and $60 \%$ sweet [weaner], salt content $=3 \%$, protein content $=22 \%$; AniproNCQ, Performance Feeds, QLD 4400, Australia) was provided ad libitum in $200 \mathrm{~L}$ feeders placed $15 \mathrm{~m}$ from the west end of the paddocks. Placement of supplement feeders aimed to increase the attractiveness of the west end area for cattle. Permanent drinking water troughs were situated $75 \mathrm{~m}$ from the east end of each paddock (Fig. 1). This paddock configuration was maintained throughout the experiment, including the period of cattle preparation.

\section{Monitoring and Stimulation Devices}

The electronics used to monitor the location of each steer and provide the stimuli were housed in a neck collar (Fig. 2) based on an earlier version of AAC equipment (Bishop-Hurley et al. 2007). The hardware consisted of a Fleck ${ }^{\mathrm{TM}} 3$ mainboard and

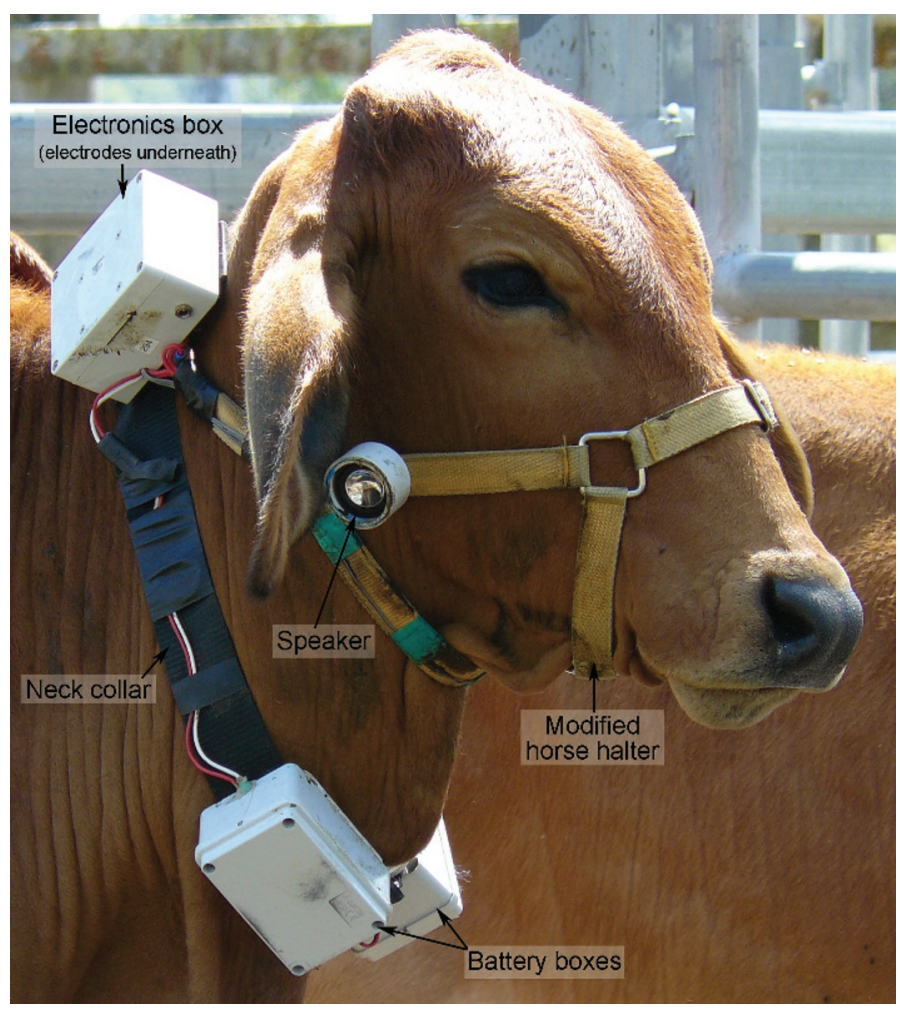

Figure 2. Steer wearing automated animal control (AAC) equipment. three daughter boards: 1) a GPS board with an antenna to determine spatial location and an integrated Secure Digital card reader to store the data, 2) an audio board to reproduce a computer-generated buzzing sound $(60 \mathrm{~dB}$ at $1 \mathrm{~m})$, and 3) a board that produced a $1 \mathrm{kV}$ electrical pulse for $1 \mathrm{~s}$. This equipment was contained in a $110 \times 70 \times 50 \mathrm{~mm}$ plastic box (electronics box) and powered by $24 \mathrm{AA} \mathrm{Ni-Mh}$ rechargeable batteries housed in two plastic boxes (12 in each battery box). A 50-mm-wide nylon neck collar attached to a modified horse halter was used to carry the equipment and kept the electronics box on top of the animals' neck for optimal GPS reception (Fig. 2). The battery boxes were secured on either side of the neck toward the bottom of the collar and acted as counterweights. Two speakers connected to the audio board were attached to the halter near the animals' left and right ear canals. Electric stimuli were delivered from a single pair of electrodes, which were fixed to the halter strap positioned on the top of cattle's neck. A dedicated program was loaded into the Fleck ${ }^{\mathrm{TM}}$ 3 and provided the set of commands used to control each device. Hereafter the device described above will be referred to as the AAC collar.

\section{Preparation of Cattle}

Thirty-seven Brahman (Bos indicus) yearling steers with an initial live weight of $312 \mathrm{~kg} \pm 26 \mathrm{SD}$ were purchased for the experiment. Once at the Research Station, the steers were inducted over $7 \mathrm{wk}$ into being handled in the yards and wearing dummy AAC collars. During this period, the steers were handled once or twice per week to either put on or take off the collars. For safety reasons, five animals were excluded from the experiment due to their aggressive behavior during the induction period. Subsequently, the remaining 32 steers were weighed again $(375 \mathrm{~kg} \pm 30 \mathrm{SD})$ and split into four groups (A, $\mathrm{B}, \mathrm{C}$, and D) of similar mean weight using a weight-stratified random procedure. Each group of eight steers was randomly assigned to an experimental paddock and kept there for $1 \mathrm{wk}$ to enable the steers to familiarize themselves with its configuration, to develop daily routines (DelCurto et al. 1999) and establish group behaviors (Launchbaugh and Howery 2005). Each cattle group was considered as an experimental unit, and a full day was the unit of time analyzed. Analyzing individual steer behaviors fell beyond the goals of this paper. However, scrutiny of the data indicated the steers behaved mostly as united groups throughout the experiment.

To maintain consistency, the same persons mustered and handled the cattle at the beginning and end of the experimental 


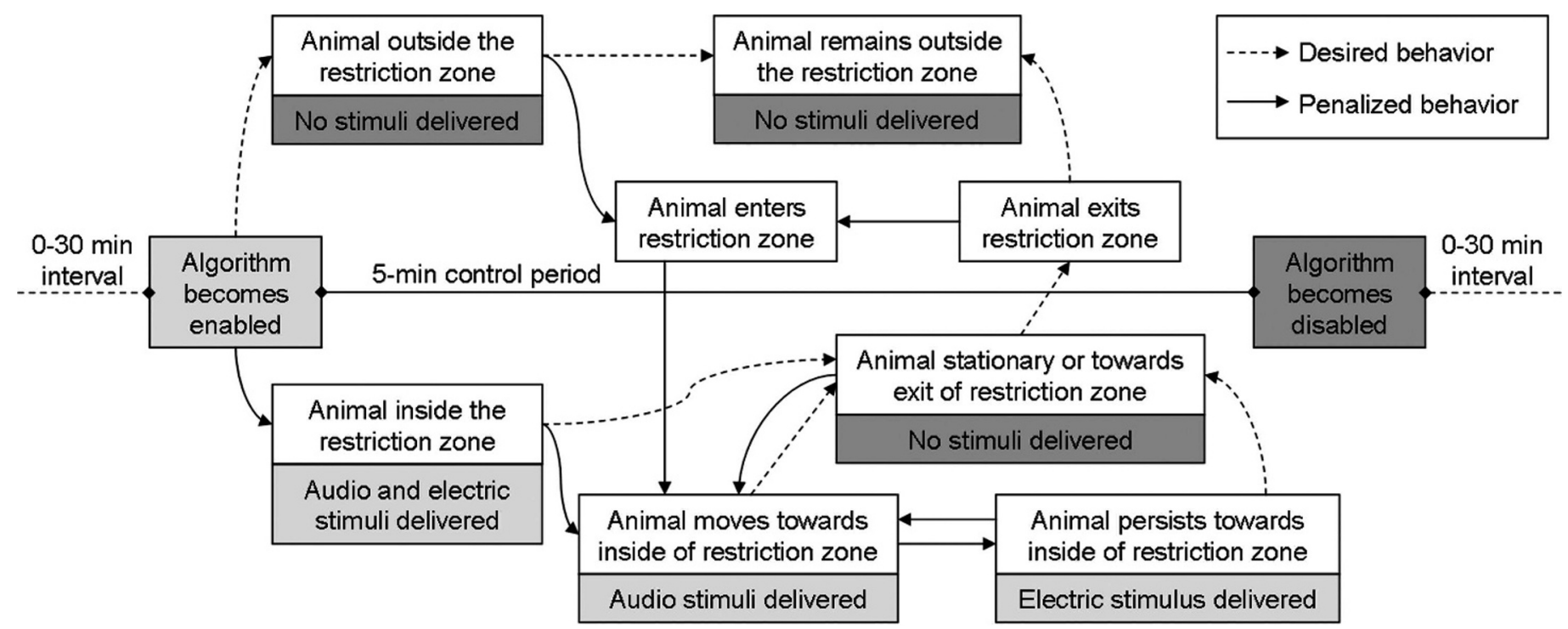

Figure 3. Decision flow followed by algorithm to determine stimuli delivery during controlled-grazing deployment (Controlled GD).

periods. To minimize the effects of mustering and handling on the experimental results, deployments began at least $1 \mathrm{~h}$ after the last group of steers had returned to its paddock. The steers were not mustered or handled during the deployments.

This experiment was approved by the Rockhampton Animal Experimentation Ethics Committee (application number RH231-07).

\section{Experimental Treatment}

Animal location data from the period when the steers received aversive stimuli was compared with the data from the period when no aversive stimuli were applied. All four groups (replicates) of steers followed the same experimental procedure. During the first $3 \mathrm{~d}$, the cattle used the resources in the paddocks in the absence of any stimuli (called free-grazing deployment [Free GD] hereafter). After a 4-d interval, a second 3 -d experimental period was run (called controlled-grazing deployment [Controlled GD] hereafter), where the steers were subjected to discontinuous aversive stimulation. All animals were fitted with AAC collars that monitored their location (Free GD and Controlled GD) and delivered the aversive stimuli (Controlled GD only). In the interval between deployments, the steers were not instrumented, and groups remained in their respective paddocks. Both deployments started with fully recharged batteries and lasted two full days (48 h), beginning at 1530 hours on Day 1 and ending at 1530 hours on Day 3. The restriction zone was defined as a rectangular strip $120 \mathrm{~m}$ long $\times 65 \mathrm{~m}$ wide at the west end of each paddock, where the supplement feeder was located (Fig. 1). This area $(0.77 \mathrm{ha} \pm 0.08 \mathrm{SD})$ represented approximately one-tenth $(10.2 \% \pm 0.9 \mathrm{SD})$ of the total area of the paddocks, which differed slightly in shape and size.

The stimulation protocol implemented in this trial (Fig. 3) was based on an algorithm previously developed for AAC, which automatically delivered stimuli proven to work in earlier experiments (Bishop-Hurley et al. 2007; Lee et al. 2007). Originally, the control algorithm continuously recorded the animal's location, and the stimuli were delivered as soon as the animal tried to enter the restriction zone. The standard stimuli consisted of a nonaversive audio cue (maximum duration of $3 \mathrm{~s})$, followed by an aversive mild $(1 \mathrm{kV})$ electric stimulus (1-s duration) if the animal attempted to cross the virtual fence line. This behavioral-based control algorithm utilized associative learning methodologies (for details, see Lee et al. 2007), as the stimulus would immediately stop if the animal adopted the desired behavior (i.e., halted or turned around). The stimuli were deactivated when a speed threshold was exceeded, avoiding unnecessary stimuli occurring to an alarmed animal. Outside the restriction zone, no stimuli were delivered.

For the experiment, the control algorithm was modified to operate discontinuously. After being enabled for a 5-min-long control period, the algorithm was disabled for intervals with a random duration of between $0 \mathrm{~min}$ and $30 \mathrm{~min}$. This procedure created, on average, 15 -min intervals between the 5-min control periods. During the intervals, the GPS remained active and provided continuous monitoring of steers but no stimuli was delivered, regardless of the location of steers in the paddocks. The interval sequence was programmed in such a way that control periods took place simultaneously for all steers in a group, and at different times for each group.

The control algorithm was also recoded to deliver a single 3s-long audio cue followed by the 1-s-long electric stimulus if the steer was inside the restriction zone when the algorithm became enabled, regardless of steer's movement in that moment. This "wake-up" feature was introduced to initiate movement of the steers, as lack of movement would have rendered the control algorithm ineffective. During the following $5 \mathrm{~min}$, those steers still inside the restriction zone would receive stimuli as would those animals attempting to enter the restriction zone (Fig. 3).

\section{Data Recorded, Processing, and Statistical Analyses}

Each steer's AAC collar recorded data twice per second throughout the experiment. Each record contained the date and time, location data (northing, easting, and UTM zone), type of GPS fix (three-dimensional [3D], two-dimensional 
Table 1. Landscape Preference Index (LPI) values for cattle groups during free-grazing deployment (Free GD) and controlled-grazing deployment (Controlled GD).

\begin{tabular}{|c|c|c|c|c|c|}
\hline \multirow[b]{2}{*}{ Zone and period } & \multicolumn{3}{|c|}{ Cattle group } & \multirow[b]{2}{*}{ Mean \pm SEM } & \multirow[b]{2}{*}{$t$ test } \\
\hline & A & B & C & & \\
\hline \multicolumn{6}{|c|}{ Restriction zone, total duration of deployments } \\
\hline Free-grazing deployment & 3.78 & 4.66 & 5.01 & $4.48 \pm 0.37$ & $t=12.42$ \\
\hline Controlled-grazing deployment & 0.11 & 0.13 & 0.17 & $0.14 \pm 0.02$ & $P=0.006$ \\
\hline \multicolumn{6}{|c|}{ Restriction zone, evolution during the controlled-grazing deployment } \\
\hline First half of deployment & 0.18 & 0.22 & 0.33 & $0.24 \pm 0.04$ & $t=4.14$ \\
\hline Second half of deployment & 0.03 & 0.04 & 0.01 & $0.03 \pm 0.01$ & $P=0.054$ \\
\hline \multicolumn{6}{|c|}{ Gate zone, total duration of deployments } \\
\hline Free-grazing deployment & 1.21 & 1.62 & 2.21 & $1.68 \pm 0.29$ & $t=-3.10$ \\
\hline Controlled-grazing deployment & 6.99 & 4.87 & 4.01 & $5.29 \pm 0.89$ & $P=0.090$ \\
\hline
\end{tabular}

[2D], or No Fix), and information regarding the algorithm and the stimuli being delivered (algorithm enabled/disabled, type of stimulation audio/electric, electrodes delivering stimuli yes/no). These records were stored on Secure Digital cards that were downloaded after each deployment. Data were parsed using Matlab 7.7 (MathWorks, Natick, MA) and summarized using MS Office Access 2003 (Microsoft Corp., Redmond, WA) and ArcGIS 9.3 software (ESRI, Redlands, CA), including Hawth's Analysis Tools 3.27 extension for ArcGIS (Beyer 2004).

Records with poor GPS fix quality (i.e., 2D and No Fix) were deleted from the datasets. If less than $95 \%$ of the total daily records (172 800) of an AAC collar had 3D precision, it was considered to have been malfunctioning, and its dataset was discarded. Furthermore, 3D records more than $5 \mathrm{~m}$ outside the paddock boundaries (mean $=0.04 \%$ ) were also removed. Those records within the $5-\mathrm{m}$ buffer around the boundaries were considered to be near-fence fixes drifted by the GPS error.

The number of AAC collars operating correctly (i.e., functional electronics recording GPS positions and generating the stimuli due) decreased progressively in both deployments. In the course of the $48 \mathrm{~h}$ of Free GD, the mean (and minimum) number of functional units in the cattle groups went down from 7 (5) to 5 (3). In Controlled GD, this number decreased from 5 (4) to 3 (2). Unfortunately, the electrodes of the two collars that were still working in one of the groups at the end of Controlled GD failed to deliver electric stimuli in the last hours of the deployment. The data from this group were, therefore, excluded from the statistical analysis. No collars delivered audio or electric stimuli outside the programmed times and areas.

The grazing behavior of cattle was analyzed through a Landscape Preference Index (LPI). Generically, LPI could be defined as "the ratio between the proportional time spent in an area of interest and the proportion of the area of interest compared to the whole area available" (Handcock et al. 2009, p. 3597). LPI values were computed for the restriction zone and the total duration $(48 \mathrm{~h}$ ) of each deployment, and they were compared to determine the global effectiveness of the discontinuous stimulation in reducing the preference of the steers for the restriction zone.

LPI for the restriction zone was also calculated separately for the first and second halves of Controlled GD. Comparison of these two 24-h periods was used to assess how progressive learning impacted behavior in cattle. Furthermore, understanding how avoidance of the restriction zone affected the use of the rest of the paddocks was also of interest. This effect was assessed in another preferred but unrestricted area: the gate zone located at the opposite (east) end of the paddocks (Fig. 1). LPI values for the gate zone were computed for the total duration of each deployment.

The duration of cattle visits to the restriction zone was calculated as the length of time between the first animal in the group entering the area and the last animal leaving it. The time cattle groups spent outside the restriction zone between two consecutive visits (the return interval) was also measured. The mean duration of visits and the mean return interval were computed for each cattle group, and these values were compared between deployments.

The Controlled GD was further analyzed to determine the number of steers that entered the restriction zone in each visit and the amount and type of stimuli delivered. Steers' response to the stimuli was evaluated based on the time it took for the group to leave the restriction zone after the start of the stimuli. The mean distance from the location of the stimulated steers to the virtual boundary of the restriction zone at the start of the stimuli was also calculated. All these parameters were determined by detailed scrutiny of the data recorded on AAC collars.

Analyses were completed using the R v. 2.9.1 statistics software package (R Development Core Team 2009). Deployments were compared through paired Student's $t$ tests, and the normality in the distribution of the data was tested for using the Shapiro-Wilk W test.

\section{RESULTS}

The random discontinuous application of stimuli modified the grazing behavior of the cattle, and it therefore constitutes a useful addition to existing automated animal control algorithms. All four steer groups reacted consistently by avoiding the restriction zone where the stimuli were applied. The failure of the AAC collars in Group D gave this group nonstimulated access to the restriction zone toward the end of Controlled GD. Accordingly, the statistical analyses were carried out with the data only from Groups A, B, and C, and the distinct behavior observed in Group D is reported separately.

The LPI for the restriction zone in Controlled GD (0.14) was $3.1 \%$ of that observed in Free GD (4.48). This difference was highly significant (Table 1) and proved that grazing behavior of 


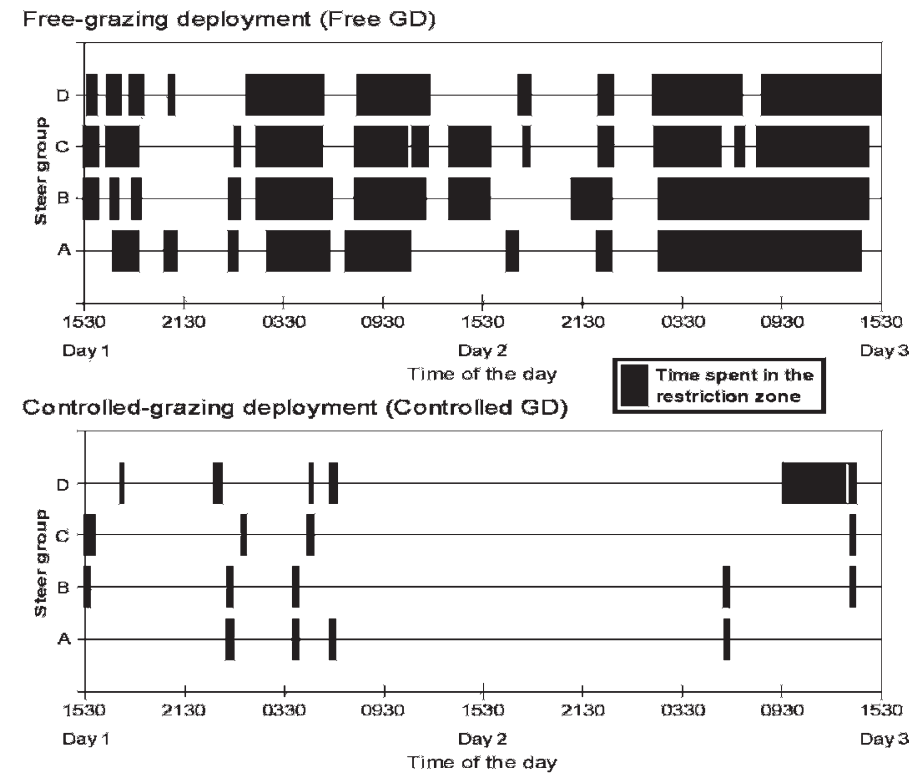

Figure 4. Time steer groups spent inside the restriction zone during free-grazing deployment (Free GD) and controlled-grazing deployment (Controlled GD).

the steers was successfully modified by the experimental treatment, resulting in a drastic reduction of steer use of the restriction zone.

LPI values between the first and second halves of Controlled GD showed a clear decreasing trend. In the first $24 \mathrm{~h}$, LPI for the restriction zone was already very low (0.24) compared with Free GD, but it further diminished to a negligible value (0.03) in the second half of the deployment. However, the difference between the two halves was only marginally significant (Table 1).

The restriction zone was the most preferred area during Free $\mathrm{GD}$, followed by the gate zone ( $\mathrm{LPI}=1.68)$, located at the opposite end of the paddocks. The aversive stimulation implemented during Controlled GD in the restriction zone produced a noticeable increase in steer preference for the gate zone (LPI $=5.29)$. However, the small number of replicates ( $n=3$, as Group D was excluded from the analyses) limited the statistical significance of this increase (Table 1).

In the 48 hours of Free GD, the mean number of visits to the exclusion zone per cattle group was $9.7 \pm 1.2 \mathrm{SEM}$. The mean duration of the visits was $2 \mathrm{~h} 39 \mathrm{~min} \pm 19 \mathrm{~min}$, while the mean return interval was 2 h $33 \mathrm{~min} \pm 18 \mathrm{~min}$. During Controlled $\mathrm{GD}$, the mean number of visits per group was reduced to $4.3 \pm 0.3$, and the mean time cattle spent inside the restriction zone was $10 \pm 1 \mathrm{~min}$. The mean return interval was $12 \mathrm{~h}$ $8 \mathrm{~min} \pm 1 \mathrm{~h} 36 \mathrm{~min}$. According to the statistical tests, the duration of visits was significantly shorter $(t=7.68, P=0.017)$ in Controlled GD, while the return interval between visits was longer $(t=-5.09, P=0.037)$.

During Free GD, the longest visits to the restriction zone were concentrated during the night and the morning (Fig. 4). In Controlled GD, the first (three to four) visits of each group were concentrated in the first $15 \mathrm{~h}$ of the deployment and lasted $31 \mathrm{~min}$ at most (Table 2). Afterwards, no visits to the restriction zone took place for a period that lasted between $24 \mathrm{~h}$ and $32 \mathrm{~h}$ across the groups. Toward the end of the deployment, all groups revisited the restriction zone but remained there for very short ( $<10 \mathrm{~min}$ ) periods, with the exception of Group D.

The stimuli delivered to the four groups of cattle throughout each visit to the restriction zone during Controlled GD is

Table 2. Characterization of cattle-group visits (time, steers monitored, visit duration) to the restriction zone during controlled-grazing deployment (Controlled GD), including stimuli delivered (audio and electric) and the reaction of the group (time and distance to exit).

\begin{tabular}{|c|c|c|c|c|c|c|c|c|}
\hline Group-visit & $\begin{array}{l}\text { Time from start of } \\
\text { deployment } \\
\text { (h:min:s) }\end{array}$ & $\begin{array}{l}\text { No. of visiting } \\
\text { steers monitored }\end{array}$ & $\begin{array}{l}\text { Visit duration } \\
\text { (h:min:s) }\end{array}$ & $\begin{array}{l}\text { Mean distance to } \\
\text { exit at start of } \\
\text { stimuli }(\mathrm{m})\end{array}$ & $\begin{array}{l}\text { Time from start of } \\
\text { stimuli until exit } \\
\text { (h:min:s) }\end{array}$ & $\begin{array}{l}\text { Audio stimuli } \\
\text { per steer (s) }\end{array}$ & $\begin{array}{l}\text { No. of electric } \\
\text { stimuli delivered }\end{array}$ & $\begin{array}{l}\text { No. of steers that } \\
\text { received electric } \\
\text { stimuli }\end{array}$ \\
\hline$A-1$ & $8: 35: 50$ & 4 & $0: 16: 24$ & 28.5 & 0:05:18 & 24.8 & 29 & 4 \\
\hline A-2 & 12:38:12 & 4 & 0:09:08 & $N A^{1}$ & $N A^{1}$ & 0.0 & 0 & 0 \\
\hline$A-3$ & $14: 52: 19$ & 4 & 0:07:51 & 9.3 & 0:00:10 & 2.9 & 3 & 3 \\
\hline$A-4$ & $38: 36: 55$ & 4 & 0:07:45 & $N A^{1}$ & $N A^{1}$ & 0.0 & 0 & 0 \\
\hline B-1 & 0:00:00 & 4 & 0:11:56 & 47.0 & 0:05:09 & 16.6 & 4 & 3 \\
\hline B-2 & 8:37:34 & 4 & 0:13:48 & 29.5 & 0:02:27 & 3.5 & 2 & 2 \\
\hline B-3 & $12: 38: 07$ & 4 & 0:08:01 & 23.5 & 0:01:12 & 3.5 & 2 & 2 \\
\hline B-4 & $38: 35: 58$ & 2 & 0:09:47 & 10.5 & 0:03:32 & 14.3 & 3 & 1 \\
\hline B-5 & $46: 17: 40$ & 3 & 0:01:31 & 11.0 & $0: 00: 23$ & 3.3 & 0 & 0 \\
\hline$C-1$ & 0:00:00 & 5 & 0:30:52 & 54.1 & 0:02:05 & 6.5 & 4 & 4 \\
\hline$C-2$ & 09:32:35 & 3 & 0:00:37 & 0 & 0:00:37 & 5.0 & 3 & 1 \\
\hline$C-3$ & $13: 30: 20$ & 5 & $0: 11: 51$ & 47.1 & 0:02:18 & 6.6 & 4 & 3 \\
\hline$C-4$ & $46: 17: 49$ & 4 & 0:01:43 & $N A^{1}$ & $N A^{1}$ & 0.0 & 0 & 0 \\
\hline D-1 & 02:10:02 & 2 & 0:00:34 & 0 & $0: 00: 34$ & 2.8 & 0 & 0 \\
\hline D-2 & $07: 53: 58$ & 5 & 0:15:10 & 31.1 & 0:00:16 & 3.3 & 5 & 5 \\
\hline D-3 & $13: 37: 00$ & 3 & 0:02:29 & 0 & 0:02:29 & 1.7 & 0 & 0 \\
\hline D-4 & $14: 49: 09$ & 5 & $0: 16: 44$ & 52.3 & 0:10:59 & 23.6 & 17 & 4 \\
\hline D-5 & 42:08:08 & 2 & 3:49:19 & 0 & 3:49:19 & 126.8 & 0 & 0 \\
\hline D-6 & 46:08:32 & 1 & 0:16:03 & 0 & 0:16:03 & 43.0 & 0 & 0 \\
\hline
\end{tabular}

${ }^{1} \mathrm{NA}$ : not applicable; algorithm was disabled throughout the visit. 
summarized in Table 2. Leaving aside the visits where the stimulation failed (D-5 and D-6), the mean time from the start of the stimuli until all steers exited the area was $2 \mathrm{~min}$ $41 \mathrm{~s} \pm 47 \mathrm{~s}$ SEM. Two consecutive stimulation cycles were needed in D-4 to make the animals exit the restriction zone. In three other visits (A-1, B-1, and C-2) the 5-min stimulation period finished before the last animal of the group exited, but in all three cases this took place less than $20 \mathrm{~s}$ prior to the animals' leaving the restriction zone. Even though the algorithm was enabled in both D-1 and D-3 when animals entered the restriction zone, their movements were mostly along the virtual boundary, so they did not trigger any electric stimuli and few audio cues. In B-2, B-3, B-4, and C-2, one or two of the steers received the electric stimuli and the rest of the group only received audio cues, but all steers exited the restriction zone.

D-5 and D-6 were the visits made by Group D to the restriction zone where, due to technical failure, no electric stimuli were delivered to any of the steers of the group (Table 2). In the first of these visits (D-5), the steers perceived immediately the lack of aversive stimuli and rested in the restriction zone for $3 \mathrm{~h} 49 \mathrm{~min}$. As a result, LPI values for the restriction zone incremented in Group D between the first half (0.20) and the second half (1.57) of Controlled GD. The contrast with Free GD $(\mathrm{LPI}=4.42)$ was still clear, but the overall use of the restriction zone was much greater than in the other three cattle groups (Table 1).

\section{DISCUSSION}

Automated animal control (AAC) is a new technology that promises assistance in controlling animal location to managers of extensive livestock farms. This study builds on previous AAC research (Butler et al. 2006; Anderson 2007; Bishop-Hurley et al. 2007; Lee et al. 2007) by validating the hypothesis that discontinuous AAC monitoring and aversive stimulation can significantly modify the grazing behavior of cattle groups and reduce their preference for a restriction zone. This finding supports the use of discontinuous AAC to improve power efficiency in AAC systems, which constitutes an important step forward in the research that could make this technology commercially applicable in the future.

The results from our replicated experiment demonstrated a clear statistical difference in the preference indices for the restriction zone between controlled and free-grazing steers (Table 1). Taking into account that the AAC collars delivered stimuli only $25 \%$ of the time during their deployment, the $96.9 \%$ reduction observed in the use of the restriction zone can be considered very satisfactory. The somewhat divergent behavior observed in one of the replicates was caused by technical limitations detailed below and served to confirm that, as long as the aversive stimuli are effectively delivered, random discontinuous AAC operation is able to reduce the use of an area by steers.

Steer groups were expected to increasingly avoid the restriction zone as a consequence of receiving successive aversive stimuli. The mean LPI values of the first and the second halves of Controlled GD ( 0.24 and 0.03 , respectively) seemed to confirm this hypothesis, but differences were not statistically clear $(P=0.054)$. In fact, LPI values for the restriction zone were already very low even in the first $24 \mathrm{~h}$ of the deployments, which suggests that steers learned very rapidly to avoid the area. Indeed, the experimental steers were strongly discouraged from entering the restriction zone for some time (24-32 h) after their first three to four visits (Fig. 4). A similar number of aversive stimuli were needed in another experiment until cattle associated an audio cue to the subsequent electric stimulus (Bishop-Hurley et al. 2007). Rapid associative learning has also been reported by Lee et al. (2007) who analyzed cattle response to receiving electrical stimuli when they approached a feed attractant.

The avoidance of the restriction zone was expected to influence how the steers used the rest of the paddocks. The important increase observed in the preference shown for the gate zone (Table 1) captured this effect clearly. This zone contained the gate to the paddock, was close to the drinking water trough, and was the area farthest from the restriction zone (Fig. 1). All these features probably contributed to the remarkably high frequentation of the gate zone $(\mathrm{LPI}=5.29)$ registered during Controlled GD. This result could be considered a warning about restricting the access to a preferred area: Restriction may result in very high impact in other areas of the paddock.

The statistical analyses indicated that during Controlled GD not only were LPI values lower, but visits to the restriction zone were shorter in duration $(P=0.017)$, and the mean return interval was longer $(P=0.037)$ than during Free GD (Fig. 4). These findings demonstrate that the stimuli and their protocol for being applied elicited the desired animal behavior in our experiment. The degree of intervention applied can be summarized as 5-min-long control periods on a random sequence with a mean interval (without stimulation) of $15 \mathrm{~min}$. Randomizing the time interval between control periods was considered important to prevent animals from learning that exploring the restriction zone in the first minutes following a control period was always "safe." The randomized approach was successful in our experiment, but no complementary tests were run with a nonrandomized sequence to determine the importance of this characteristic.

In most of the visits steers made to the restriction zone (Table 2 ), one control period (5 min) sufficed to make animals exit the restriction zone. This indicated that this was an adequate duration for our experimental setup, which comprised relatively small ( $<1 \mathrm{ha}, 10 \%$ of the paddocks) and distinct restriction zones (Fig. 1). Three $(16 \%)$ of the visits, however, were completed during an interval when the algorithm was disabled (Table 2). Learning of appropriate responses could have been disrupted by this location-stimuli association inconsistency (Lee et al. 2007). However, none of these three visits lasted for more than $10 \mathrm{~min}$. The association of features in the restriction zone (most importantly, the supplement feeder) with an aversive stimuli did not last very long. Delivery of electric stimuli was necessary to maintain avoidance behavior toward the end of Controlled GD; when not delivered, as in Group D, steers restarted to use the restriction zone.

The distinct behavior of Group D was caused by technical failure of the two AAC collars that were still working at visits D-5 and D-6 (Table 2). Collars failed to deliver electric stimuli, most probably due to a defective contact between the electrodes 
and the steers' skin. This undesirable result calls for an improvement in the interface between AAC collars and animals. There were other collars that failed to deliver electric stimuli, but on only one other occasion (B-5) did all collars in the group fail. In these cases, however, the audio cues proved effective in ensuring the cattle did not stay in the restriction zone. In a replicated experiment with similar stimulation (Bishop-Hurley et al. 2007), cattle also responded appropriately to the audio cue after having previously experienced audio cues followed by electric stimuli. The response to audio stimuli, however, has been reported to wane as cattle get habituated (Butler et al. 2006), and the application of an aversive stimulus would be, at some point, necessary to maintain avoidance (Nolte 1999). The behavior observed in Group D toward the end of Controlled GD seems to support this assertion.

The number of AAC collars operating correctly decreased progressively in both deployments. As collars failed, fewer steers were monitored, so the behavior of the whole cattle group had to be inferred from the behavior of fewer animals. This assumption was supported by scrutiny of the data, including periods with many functional collars, which showed that steers behaved mostly as united groups throughout the deployments. However, it was anticipated that fewer functional collars would be less effective in encouraging the whole cattle group to leave the restriction zone, as fewer steers would potentially receive the stimuli. Nevertheless, there were four visits to the restriction zone (i.e., B-2, B-3, B-4, and C-2) in which only one or two animals (out of the two to four with functional collars) received electric stimuli, but it was still possible to successfully have all steers exit the restriction zone. This result suggests that it may not be necessary to instrument all animals within a commercial AAC application (Anderson 2007).

Although the AAC collars were programmed to deliver stimuli during only $25 \%$ of the deployment time, their GPS remained activated throughout the deployments. Indeed, recording high frequency GPS positions was necessary to provide continuous monitoring of steers, and this caused high battery consumption, which led to short-duration experimental deployments ( $3 \mathrm{~d}$ ). In commercial applications, however, the designed duty cycling could allow the AAC collar (including the GPS) to be in stand-by for $75 \%$ of the time; this would represent a fourfold increase in deployment time based on the energy saved.

\section{Future Research}

In future research, further reductions in power consumption of AAC collars may require additional algorithm modifications. A simplified algorithm that delivered an occasional electric stimulus to cattle when inside a restriction zone may be sufficient to initiate avoidance behavior. Indeed, the frequency of these stimuli could possibly be reduced as cattle progressively learned to avoid the area. A more complex algorithm could also be of interest, if it estimated the probability of an animal entering a restriction zone in the subsequent period of time (Swain et al. 2008b) or predicted the most probable length of time until the animal reached the restriction zone. This would reduce the frequency with which AAC collars would need to be activated and diminish energy consumption. These algorithms should be designed to work with low GPS fix frequency, as this would also save energy in commercial applications. Other AAC challenges also need to be researched, such as improving the animal-borne equipment or determining whether AAC is still effective when only part of the herd (i.e., group leaders) are collared.

\section{IMPLICATIONS}

Our results suggest that the aversive stimuli provided by discontinuously activated AAC collars can suffice to significantly modify the grazing behavior of groups of cattle and reduce their preference for a restriction zone. This finding constitutes an important step forward in improving power efficiency in AAC systems, as it suggests that AAC collars can be duty cycled to save energy while still delivering successful animal control. This approach focuses on reducing grazing impact on a zone delimited by a permeable virtual boundary, rather than attempting to obtain complete control of livestock along a virtual fence line. Further research is still needed before livestock management in extensive rangelands benefits from AAC commercial applications.

\section{ACKNOWLEDGMENTS}

The authors would like to thank Karina Tane, Christopher O’Neill, Chris Crossman, Philip Valencia, ICT Centre staff, Rob Young the farm manager, and Belmont Research Station staff for their assistance in carrying out the experimental work. The authors acknowledge constructive comments made on an earlier version by two referees and the Associate Editor.

\section{LITERATURE CITED}

Anderson, D. M. 2007. Virtual fencing: past, present and future. Rangeland Journal 29:65-78.

Balley, D. W. 2005. Identification and creation of optimum habitat conditions for livestock. Rangeland Ecology \& Management 58:109-118.

BEYER, H. L. 2004 [computer software]. Hawth's analysis tools for ArcGIS. Version 3.27. Available at: http://www.spatialecology.com/htools.

Bishop-Hurley, G. J., D. L. Swain, D. M. Anderson, P. Sikka, C. Crossman, and P. Corke. 2007. Virtual fencing applications: implementing and testing an automated cattle control system. Computers and Electronics in Agriculture 56:14-22.

Broom, D. M., and A. F. Fraser. 2007. Domestic animal behaviour and welfare. Cambridge, UK: Cab International. 540 p.

Butler, Z., P. Corke, R. Peterson, and D. Rus. 2006. From robots to animals: virtual fences for controlling cattle. International Journal of Robotics Research 25:485-508.

DelCurto, T., M. Porath, M. Mclnnins, P. Momont, and C. Parsons. 1999. Management strategies for optimal beef cattle distribution and use of mountain riparian meadows. In: K. L. Launchbaugh, K. D. Sanders, and J. C. Mosley [EDS.]. Grazing behavior of livestock and wildlife. Moscow, ID, USA: University of Idaho. p. 119-129.

GansKoPP, D. 2001. Manipulating cattle distribution with salt and water in large arid-land pastures: a GPS/GIS assessment. Applied Animal Behaviour Science 73:251-262.

Handcock, R. N., D. L. Swain, G. J. Bishop-Hurley, K. P. Patison, T. Wark, P. Valencia, P. Corke, and C. J. O'NellL. 2009. Monitoring animal behaviour and environmental interactions using wireless sensor networks, GPS collars and satellite remote sensing. Sensors 9:3586-3603. 
Launchbaugh, K. L., and L. D. Howery. 2005. Understanding landscape use patterns of livestock as a consequence of foraging behavior. Rangeland Ecology \& Management 58:99-108.

Lee, C., K. Prayaga, M. Reed, and J. Henshall. 2007. Methods of training cattle to avoid a location using electrical cues. Applied Animal Behaviour Science 108:229-238.

NoLTE, D. 1999. Behavioral approaches for limiting depredation by wild ungulates. In: K. L. Launchbaugh, K. D. Sanders, and J. C. Mosley [EDS.]. Grazing behavior of livestock and wildlife. Moscow, ID, USA: University of Idaho. p. 60-69.

Pienaar, D. J., J. d. P. Bothma, and G. K. Theron. 1992. Landscape preference of the white rhinoceros in the southern Kruger National Park. Koedoe 35:1-7.

R Development Core Team [computer software]. 2009. R: a language and environment for statistical computing. Version 2.9.1. Vienna, Austria: R Foundation for Statistical Computing.

Ruiz-Mirazo, J., A. B. Robles, and J. L. González-Rebollar. 2009. Pastoralism in natural parks of Andalucía (Spain): a tool for fire prevention and the naturalization of ecosystems. In: F. Pacheco and P. Morand-Fehr [EDS.]. Changes in sheep and goat farming systems at the beginning of the 21st century. Zaragoza, Spain: CIHEAM-IAMZ. p. 141-144.

Senft, R. L., M. B. Coughenour, D. W. Bailey, L. R. Rittenhouse, O. E. Sala, and D. M. SwIFT. 1987. Large herbivore foraging and ecological hierarchies. BioScience 37:789-799.

Swain, D. L., M. A. Friend, R. W. Mayes, L. A. Wilson, and M. R. Hutchings. 2008a. Combining an active transponder system with sprayed n-alkanes to quantify investigative and ingestive grazing behaviour of dairy cattle in pastures treated with slurry. Applied Animal Behaviour Science 109:211-222.

Swain, D. L., T. WARK, AND G. J. BISHOP-HuRLEy. 2008b. Using high fix rate GPS data to determine the relationships between fix rate, prediction errors and patch selection. Ecological Modelling 212:273-279.

Wark, T., P. Corke, P. Sikka, L. Klingbeil, Y. Guo, C. Crossman, P. Valencia, D. Swain, AND G. BISHOP-HURLEY. 2007. Transforming agriculture through pervasive wireless sensor networks. IEEE Pervasive Computing 6:50-57. 